\title{
Liberação In Vitro de Cloridrato de Ciprofloxacina em Compósitos Hidroxiapatita:Colágeno
}

\author{
Claudia A. Ogawa, Ana Maria G. Plepis \\ Instituto de Química de São Carlos, USP
}

\begin{abstract}
Resumo: Compósitos hidroxiapatita:colágeno (HA:col) foram preparados em diferentes proporções para determinar qual a melhor proporção para a incorporação de cloridrato de ciprofloxacina. Foi utilizado colágeno submetido a tratamento alcalino (24 e 48h) e a melhor proporção HA:col obtida foi de 10:1 $(\mathrm{m} / \mathrm{m})$, utilizada para incorporação e liberação de ciprofloxacina. Os experimentos de liberação in vitro foram realizados em tampão fosfato salino (PBS), $\mathrm{pH} \mathrm{7,4,} \mathrm{a} 37^{\circ} \mathrm{C}$, mostrando uma liberação máxima em torno de $90 \%$ para HA:col 24h e 75\% para HA:col 48h, após 10h de imersão. A liberação de ciprofloxacina dos compósitos é controlada pelos poros da matriz, pois segue o modelo de Higuchi. Os resultados indicam que os diferentes tempos de tratamento alcalino no colágeno afetam a liberação de antibiótico. Uma diferença na quantidade de cargas negativas nos colágenos de 24 e 48 h provocaria uma diferente interação entre o compósito e o antibiótico.
\end{abstract}

Palavras-chave: Hidroxiapatita, colágeno, liberação controlada, ciprofloxacina.

\section{In Vitro Release of Ciprofloxacin in Hydroxyapatite: Collagen Composites}

Abstract: Hydroxyapatite: collagen (HA:col) composites were prepared in different proportions in order to obtain the best one to incorporate ciprofloxacin. Collagen with alkaline treatment ( 24 and $48 \mathrm{~h}$ ) was used. The best HA:col proportion was found to be 10: $1(\mathrm{w} / \mathrm{w})$ wich was used for ciprofloxacin incorporation and release studies. Release experiments in vitro were made in saline phosphate buffers (PBS), $\mathrm{pH} 7.4$, at $37^{\circ} \mathrm{C}$, showing a maximum release approximately $90 \%$ for HA:col $24 \mathrm{~h}$ and $75 \%$ for HA:col $48 \mathrm{~h}$, after 10 hours of immersion. The ciprofloxacin delivery in the composites is controlled by matrix porous since it follows Higuchi's model. Results indicate that different times of alkaline treatment of collagen affect the antibiotic delivery rate. A different quantity of charges in collagens within $24 \mathrm{~h}$ and $48 \mathrm{~h}$ would induce a different interaction between the composite and the antibiotic.

Keywords: Hydroxyapatite, collagen, controlled delivery, ciprofloxacin.

\section{Introdução}

No tecido ósseo, a limitada circulação sangüínea reduz o efeito terapêutico das drogas administradas no modo convencional. A incorporação de drogas em biomateriais implantáveis apresenta a vantagem da liberação da droga diretamente no tecido danificado, em altas concentrações, resolvendo, então, o problema do reduzido efeito terapêutico da administração no modo convencional. Sistemas de liberação biodegradáveis apresentam ainda a vantagem de não exigirem posterior cirurgia para remoção do material após a liberação total da droga. A idéia de liberação controlada de substâncias biologicamente ativas já é utilizada desde a década de 50 , sendo que anteriormente não se conheciam materiais que pudessem liberar moléculas de alto peso molecular, tais como peptídeos e proteínas, sem induzir inflamações ${ }^{[1]}$, mas este problema foi resolvido com o desenvolvimento de novos materiais poliméricos. Atualmente definese como sistemas de liberação controlada aqueles nos quais o agente ativo é liberado independentemente

Autor para correspondência: Ana Maria G. Plepis, USP, Instituto de Química de São Carlos, Caixa Postal 780, CEP: 13566-590, São Carlos, SP. E-mail: amplepis@iqsc.sc.usp.br 
de fatores externos e com uma cinética bem estabelecida $^{[2]}$.

O sistema de liberação controlada oferece algumas vantagens sobre os métodos convencionais que liberam o agente ativo em um curto período de tempo. Algumas delas são: manutenção de níveis constantes de droga no organismo, implicando em uma eficiência maior na utilização do agente (ou seja, é necessário menor teor de droga para produzir o mesmo efeito que os sistemas convencionais); aplicação do agente diretamente no sítio de ação, produzindo altas concentrações localizadas e evitando efeitos colaterais sistêmicos, já que a droga é, na maior parte, liberada localmente; menor freqüência de administração do agente ativo, aumentando o conforto do paciente e a eficácia do tratamento.

Sistemas de liberação de drogas à base de fosfato de cálcio estão em investigação ${ }^{[3,4]} \mathrm{e}$, em muitos dos casos, estão ainda limitados apenas à liberação de drogas in vitro com compostos modelo tais como hormônios de crescimento ${ }^{[5]}$, antibióticos ${ }^{[6]} \mathrm{e}$ quimioterápicos ${ }^{[7]}$. Os trabalhos com experimentos em animais mostram que este tipo de sistema de liberação de drogas suportadas em biocerâmicas é promissor para o controle de infecções ósseas ${ }^{[3,8]}$.

Compósitos hidroxiapatita:colágeno (HA:col) são biomateriais em potencial porque seus componentes individuais possuem características essenciais a um biomaterial. O colágeno promove cicatrização de fraturas e regeneração óssea e é também um agente hemostático ${ }^{[9]}$. Além disso, possui baixo índice de irritabilidade ou alergenicidade (2\%), é biodegradável, possui habilidade em promover crescimento celular e é de fácil obtenção. $\mathrm{O}$ aspecto mais importante na utilização de colágeno na forma de compósitos com biocerâmicas é o fato desta proteína ser a matriz em que os sais de fosfato de cálcio se depositam para dar origem ao tecido ósseo ${ }^{[10]}$. A hidroxiapatita tem sido amplamente utilizada na preparação de compósitos devido à sua similaridade com o tecido calcificado do osso humano. Apresenta fragilidade característica das cerâmicas ${ }^{[11]}$, portanto, sua combinação com colágeno torna seu uso como biomaterial mais vantajoso.

O cloridrato de ciprofloxacina foi o antibiótico escolhido neste trabalho em virtude de sua conhecida utilização no tratamento de osteomielite ${ }^{[12,13]}$. Além de ser utilizado no tratamento de infecções em ossos ou juntas, o cloridrato de ciprofloxacina pode ser utilizado tam- bém em otorrinolaringologia e oftalmologia e em infecções nos tratos urinário e respiratório, infecções de pele, intra-abdominais, infecções no trato gastrointestinal, ginecológicas, de sangue. O cloridrato de ciprofloxacina pertence à família das fluoroquinolonas, antibióticos que exibem um largo espectro de atividade contra bactérias gram-positivas e gram-negativas. Age através do bloqueio de DNA girase, que é essencial para a reprodução do DNA da bactéria. Apesar de não se ter observado efeito teratológico na utilização de cloridrato de ciprofloxacina, seu emprego na forma oral pode causar efeitos colaterais tais como náuseas, vômitos, diarréias, dores abdominais, dores de cabeça, entre outros. Assim, no caso de osteomielite, por exemplo, a incorporação de ciprofloxacina em biomateriais destinados a implantes é vantajosa por minimizar esse tipo de desconforto para o paciente, visto que a droga é liberada diretamente no sítio de ação.

Neste trabalho, serão utilizados compósitos hidroxiapatita:colágeno para estudos de incorporação e liberação in vitro de cloridrato de ciprofloxacina.

\section{Experimental}

\section{Preparo e caracterização dos materiais}

A hidroxiapatita (HA) empregada neste trabalho foi sintetizada em laboratório a partir da lenta adição de fosfato de amônia em nitrato de cálcio, sob agitação constante e atmosfera de $\mathrm{N}_{2}$ e em meio básico. $\mathrm{O}$ colágeno foi obtido de serosa porcina, por meio de tratamento em meio alcalino durante 24 ou 48 horas $^{[14]}$. Para o preparo dos compósitos foram testadas proporções de 5, 10, 15 e 20:1 de HA em colágeno. Após a mistura, retiraram-se as bolhas de ar sob vácuo, e as amostras foram colocadas em formas apropriadas. Os compósitos foram congelados em freezer, liofilizados e armazenados.

Foram utilizadas as seguintes técnicas (já discutidas em trabalhos anteriores ${ }^{[15,16]}$ ) para a caracterização da HA: espectroscopia de dispersão de raios X (EDX) por meio de um equipamento LEO 440 (LEO Electron Microscopy Ltd, Cambridge, England), utilizando-se feixe de $20 \mathrm{keV}$, cobalto como padrão e detector Oxford (Oxford Instruments Inc., Concord, USA) de silício-lítio com janela de berílio; espectroscopia no infravermelho (IV), através de um equipamento de FTIR Bomem modelo MB 102, com 4 $\mathrm{cm}^{-1}$ de resolução e número de onda de 400 a 4000 
$\mathrm{cm}^{-1}$ (amostras analisadas na forma de pastilhas com $\mathrm{KBr}$ ); e difração de raios $\mathrm{X}$, utilizando-se um difratômetro automático (ânodo rotatório) de raios $X$ RIGAKU ROTAFLEX modelo RU-200B. Também foi determinada a razão $\mathrm{Ca} / \mathrm{P}$ da hidroxiapatita, quantificando-se o fósforo através de espectroscopia no UV-vis ${ }^{[17]}$ (Espectrofotômetro de UV-visível Hitachi modelo V1100) e o cálcio por absorção atômica (Espectrofotômetro de absorção atômica com polarizador Zeeman - Hitachi modelo Z-8100).

A concentração da solução de colágeno foi determinada por liofilização e os pesos moleculares foram determinados por eletroforese em gel de poliacrilamida/SDS 7\% como descrito por Laemmli ${ }^{[18]}$ e os géis submetidos à densitometria. $\mathrm{O}$ colágeno também foi caracterizado por espectroscopia no infravermelho, calorimetria exploratória diferencial (DSC) através de um DSC 2010 da TA Instruments, utilizando-se uma taxa de aquecimento de $10^{\circ} \mathrm{C} \mathrm{min}^{-1}$ na faixa de temperatura de 10 a $450^{\circ} \mathrm{C}$, com fluxo dinâmico de $\mathrm{N}_{2}$ de 80 $\mathrm{mL} \min ^{-1}$; e microscopia eletrônica de varredura (MEV) (LEO Electron Microscopy Ltd, Cambridge, England), com um detector Oxford (Oxford Instruments Inc., Concord, USA).

Os compósitos foram caracterizados por MEV, espectroscopia de difração de raios-X, IV, DSC e teste de absorção de água.

\section{Teste de absorção de água}

A absorção de água foi estudada com amostras do compósito previamente secas em dessecador, sob atmosfera de $\mathrm{NaOH}$, a vácuo. Três amostras de cada compósito 10:1 (HA:col) pesando de 8 a $10 \mathrm{mg}$ foram imersas em $50 \mathrm{~mL}$ de água destilada, separadamente. Após determinados períodos de tempo as amostras foram removidas do meio, rapidamente secas com papel de filtro para retirar a água superficial, e imediatamente pesadas. A quantidade de água absorvida foi calculada pela Equação (1):

$$
\% \text { de água absorvida }=\frac{\left(\mathrm{m}_{\mathrm{u}}-\mathrm{m}_{\mathrm{S}}\right)}{\mathrm{m}_{\mathrm{S}}} \times 100
$$

onde $\mathrm{m}_{\mathrm{u}}$ é a massa úmida do compósito e $\mathrm{m}_{\mathrm{s}}$ é a massa seca do material.

\section{Estudos de liberação de antibiótico}

A incorporação do cloridrato de ciprofloxacina nos compósitos HA:col (10:1) foi realizada no mo- mento de preparo dos mesmos. A hidroxiapatita foi adicionada lentamente às soluções de colágeno, obedecendo-se a proporção de 10:1 (m/m). Em seguida, adicionou-se o cloridrato de ciprofloxacina em quantidade equivalente a 5 e $10 \%$ em massa total de HA:col. Os compósitos foram então congelados e liofilizados. Para os estudos de liberação in vitro, os compósitos foram cortados na forma de pequenos discos de 1,4 cm de diâmetro e de peso 50-140 mg, colados em suporte apropriado com cera de abelha e umedecidos com um volume de tampão fosfato (PBS) referente à quantidade máxima que a amostra é capaz de absorver. O estudo foi realizado em triplicata. Em seguida, imergiu-se a amostra do compósito em uma cela de acrílico termostatizada $\left(37^{\circ} \mathrm{C} \pm 0,1\right)$ contendo $100 \mathrm{~mL}$ de PBS pH 7,4, sob agitação constante. Alíquotas de $1 \mathrm{~mL}$ foram retiradas em determinados períodos de tempo e repostas com tampão fresco. As alíquotas foram diluídas para $10 \mathrm{~mL}$ com PBS e, para estimar a quantidade de cloridrato de ciprofloxacina liberada, mediu-se a absorbância no UV, em 270,6 nm através de um espectrofotômetro de UV-visível Hitachi modelo U3000. Os resultados foram analisados como porcentagem cumulativa de cloridrato de ciprofloxacina liberada no meio em função do tempo.

\section{Resultados e Discussão}

Os dados obtidos das técnicas utilizadas na caracterização da hidroxiapatita mostram que sua síntese foi bem sucedida. O espectro de EDX (Figura 1) apresentou 3 picos, referentes à excitação de um elétron da camada $\mathrm{K}$ do fósforo e dois picos referentes à excitação de dois elétrons da camada $\mathrm{K}$ do cálcio. A ausência de outros picos indica que não há elementos contaminantes.

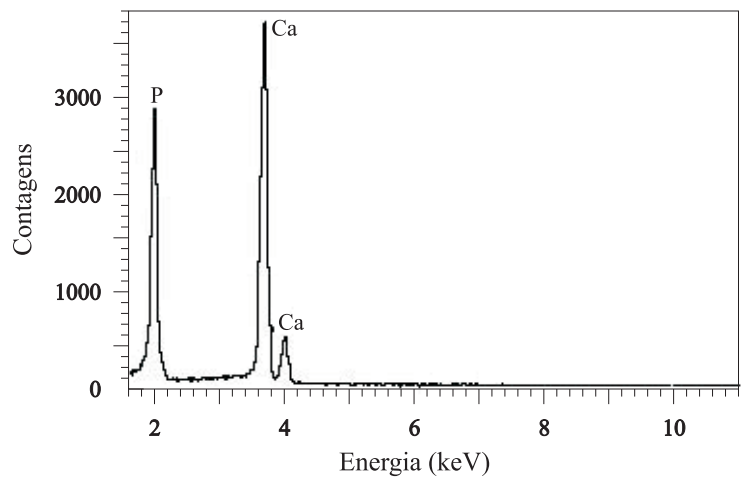

Figura 1. Espectro de dispersão de raios $\mathrm{X}$ da hidroxiapatita. 
Para verificar se o processo de preparo dos compósitos e a incorporação do cloridrato de ciprofloxacina no material não provocaram desnaturação do colágeno, analisou-se o compósito através de absorção no infravermelho e calorimetria exploratória diferencial ${ }^{[16]}$. Os espectros na região do infravermelho apresentam valores da relação das absorbâncias das bandas em 1235 e $1450 \mathrm{~cm}^{-1}$ (referentes à amida III e à ligação $\mathrm{C}-\mathrm{H}$ do anel pirrolidínico, respectivamente) próximos de 1 , mostrando que a tripla hélice do colágeno está preservada, visto que estruturas desnaturadas apresentam esses valores próximos de 0,5 . As curvas DSC obtidas para os compósitos apresentam transições em torno de $40^{\circ} \mathrm{C}$, referente à desnaturação do colágeno, confirmando o resultado já obtido por espectroscopia no infravermelho, visto que o colágeno desnaturado não apresenta transição nesta faixa. As análises foram feitas com o objetivo de se determinar a estabilidade do colágeno antes e após a preparação dos compósitos. Os espectros de difração de raios X dos compósitos apresentam perfil semelhante ao espectro obtido da hidroxiapatita. Isto era de se esperar, pois o colágeno não apresenta difratograma característico por não ser uma amostra cristalina. Também foram obtidas fotomicrografias dos compósitos a fim de se analisar a morfologia do material. Comparou-se a morfologia do material utilizado (Figura 2a) com a morfologia de um compósito idêntico, que, contudo, não foi liofilizado (Figura 2b). Pode-se verificar, para o caso do compósito HA:col 24h, que o material apresenta um aspecto homogêneo, com as partículas de hidroxiapatita totalmente agregadas às fibras de colágeno. Também se nota uma morfologia menos compacta, quando comparada à do material que não foi submetido à liofilização. Este último apresentava um aspecto rígido e não maleável, visto que, quando um material é seco naturalmente à temperatura e à pressão ambientes, o processo de secagem é mais lento, fazendo com que o material se acomode e fique com um aspecto mais compacto e rígido. Já o processo de liofilização promove uma secagem rápida do material, o que mantém uma estrutura mais porosa do mesmo.

A proporção mais adequada de HA em colágeno encontrada foi de 10:1, tanto para o colágeno de tratamento alcalino de $24 \mathrm{~h}$ como para o colágeno de $48 \mathrm{~h}$. As demais proporções ou se apresentavam quebradiças ou não proporcionaram uma manta homo-

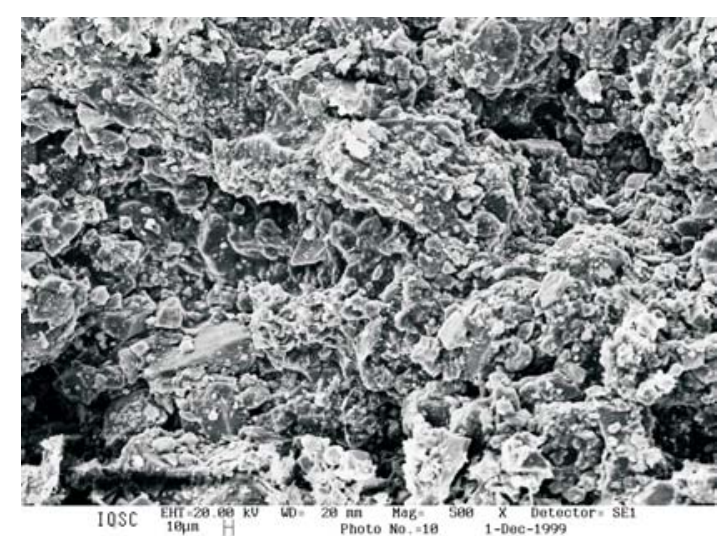

(a)

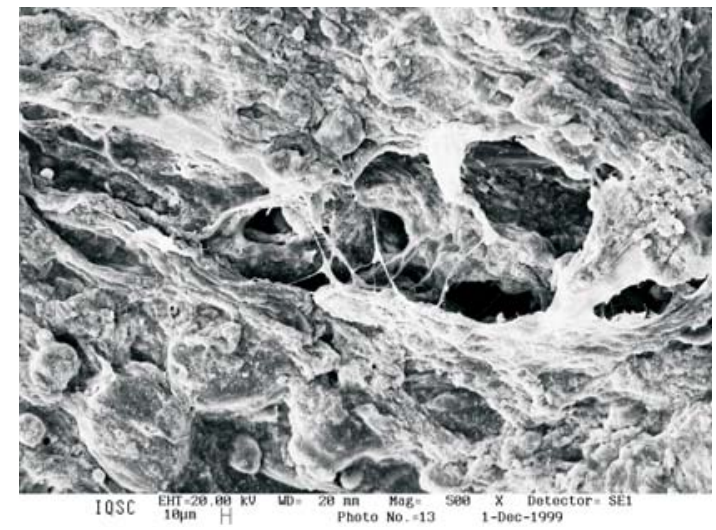

(b)

Figura 2. Fotomicrografias dos compósitos HA:col 24h (10:1) (a) obtidos sem liofilização, (b) liofilizados (ampliação de 500x).

gênea, com visíveis regiões com falta ou excesso de HA. A melhor proporção de HA em colágeno (10:1) forneceu mantas homogêneas, em que a hidroxiapatita estava totalmente agregada ao colágeno e esta composição foi a escolhida para os estudos de incorporação e liberação de cloridrato de ciprofloxacina.

\section{Teste de absorção de água}

A quantidade de água absorvida pelo compósito foi determinada em virtude da importância da hidrofilicidade para um biomaterial, visto que a taxa de absorção de água da matriz afeta a liberação da droga. A hidratação da matriz pode afetar a taxa de liberação da droga, pois aumenta a área superficial da matriz (se o processo for difusional) e, como resultado, matrizes com diferentes taxas de hidratação podem resultar em diferentes cinéticas de liberação de droga. Pode-se notar que a porcentagem de água absorvida em função do tempo de imersão (Figura 3) para o compósito HA:col $24 \mathrm{~h}$ torna-se praticamente constante após 60 minutos de imersão, mostrando que o mesmo é capaz de absorver, em média, 


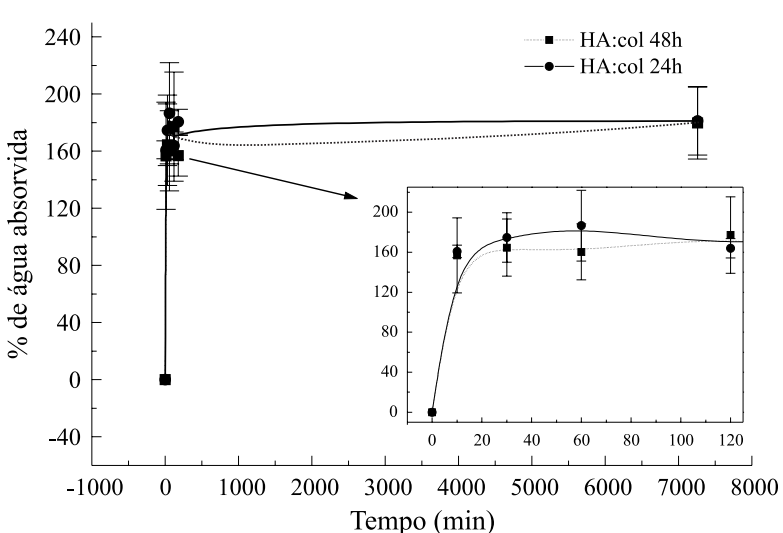

Figura 3. Porcentagem de absorção de água em função do tempo de imersão para os compósitos HA:col 10:1 preparados com colágeno de 24 e de $48 h$.

$183,2 \%$ de água, em relação à sua massa seca. O compósito HA:col $48 \mathrm{~h}$ apresentou um comportamento similar, sendo capaz de absorver, em média, $178,5 \%$ de água, em relação à sua massa, no mesmo intervalo de tempo.

\section{Estudos de liberação de antibiótico}

A Figura 4 apresenta a comparação entre a liberação de antibiótico em função do tempo de imersão em PBS obtida para os experimentos empregando-se compósitos preparados com colágeno de tratamento alcalino de 24 e $48 \mathrm{~h}$ com $5 \%$ de cloridrato de ciprofloxacina. Observa-se uma liberação de cerca de $90 \%$ após 20 horas de imersão em PBS, quando o compósito é preparado com colágeno de $24 \mathrm{~h}$. Os testes de liberação utilizando-se o compósito preparado com colágeno de 48 horas mostram uma quantia de droga liberada em torno de $80 \%$, atingindo esse valor após 20 horas de imersão. Pode-se perceber também uma pequena diferença obtida nos dois experimentos com relação à quantidade de droga inicialmente liberada, a qual é maior para o compósito HA:col 48h. Este fato poderia ser atribuído à irregularidade na superfície das amostras utilizadas ${ }^{[19]}$ ou ao tempo de tratamento alcalino do colágeno. Sabese que outros fatores afetam a liberação de drogas de biomateriais, tais como a porosidade do material utilizado $^{[7]}$ e a quantia de droga incorporada ${ }^{[20]}$. Observa-se que, quanto maior o tempo de tratamento alcalino, maior a quantidade de antibiótico inicialmente liberada. Assim, isto poderia indicar que o tratamento alcalino ao qual foi submetido o colágeno utilizado nos compósitos influencia o início da liberação.

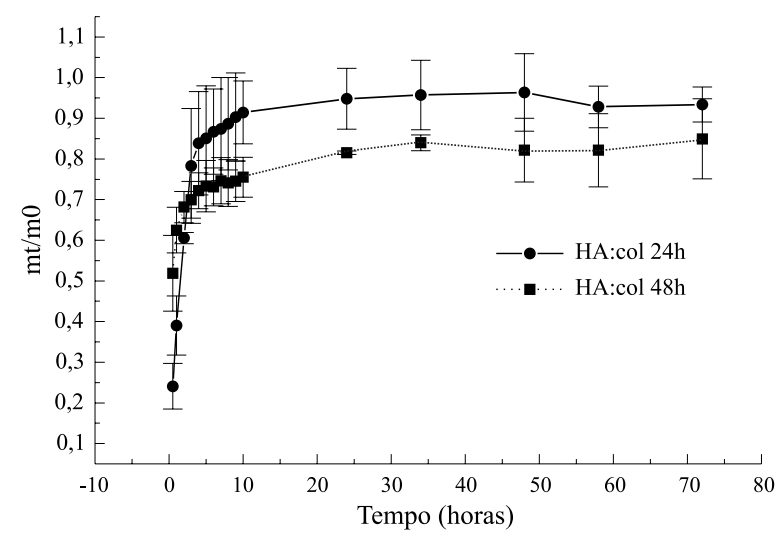

Figura 4. Comparação entre a liberação de antibiótico dos compósitos HA:col 10:1 (colágeno de tratamento alcalino de 24 e 48 h) com 5\% de cloridrato de ciprofloxacina, onde $\mathrm{mt}$ é a quantidade total liberada e $\mathrm{m} 0$ é a quantidade incorporada (em mg).

Na Figura 5 é apresentada a taxa de liberação de cloridrato de ciprofloxacina dos compósitos HA:col 24 e $48 \mathrm{~h}$ onde foi incorporado $5 \%$ de antibiótico. Verificou-se que os compósitos apresentam uma taxa de liberação decrescente com o tempo, como era de se esperar, visto que a quantia de droga liberada vai diminuindo com tempo, chegando em um valor constante em cerca de 35 horas. Esta rápida taxa de liberação pode ser vantajosa, visto que garantiria uma concentração alta de antibiótico no início de uma infecção. Por exemplo, em 10 horas de liberação temse uma taxa de liberação de cerca de $6 \mathrm{mg} \cdot \mathrm{h}^{-1}$, ou $6 \mu \mathrm{g} . \mathrm{mL}^{-1}$.h. Supondo uma ação contra Ps. aeruginosa, esta taxa seria eficaz para a inibição desta bactéria, cuja concentração inibitória mínima está entre 0.06$1 \mu \mathrm{g} / \mathrm{mL}^{[21]}$, por exemplo. Estudos realizados com compósitos HA:col na forma de pasta na proporção de 20:1, utilizando-se colágeno de serosa porcina com tratamento alcalino de 72 horas $^{[12]}$ mostram que cerca de $31 \%$ da quantia total de antibiótico incorporada é liberada após $170 \mathrm{~h}$. No caso do compósito HA:Col (10:1), na forma de manta, preparado com colágeno com tratamento alcalino de 24 e 48 horas, os resultados mostram que a liberação parece ser mais rápida, com uma liberação máxima ocorrendo logo nas primeiras 10 horas de imersão no tampão. Portanto, os resultados apontam para o fato de que, quanto maior o tempo de tratamento alcalino do colágeno empregado no compósito, mais lenta a liberação. Talvez isso se deva ao fato que quanto maior o tempo de tratamento alcalino, maior o número de cargas negativas $^{[22]}$, o que poderia provocar uma maior interação entre a matriz e o antibiótico, diminuindo a taxa de liberação. A liberação muito lenta de drogas pode não 


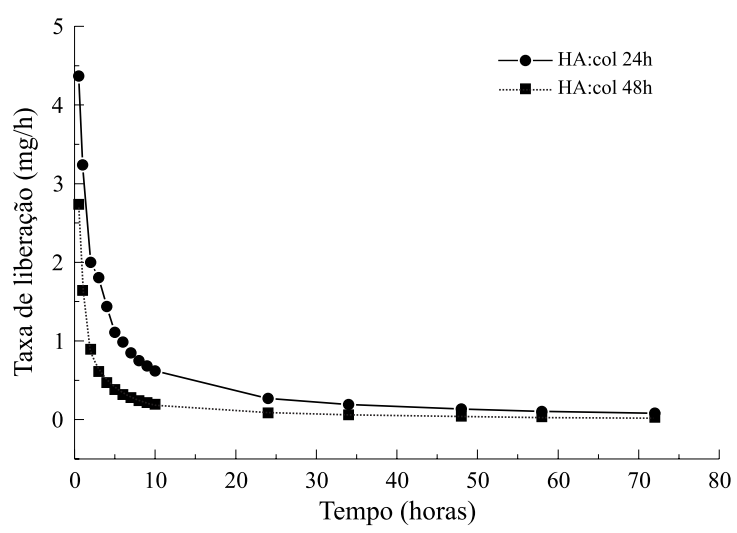

Figura 5. Comparação entre as taxas de liberação de cloridrato de ciprofloxacina dos compósitos HA:Col 24h e HA:col 48h com 5\% de antibiótico.

ser muito vantajosa, visto que poderia não surtir o efeito terapêutico desejado e até mesmo provocar resistência da bactéria ao antibiótico ${ }^{[23]}$.

A natureza das curvas mostradas na Figura 4 sugere que nenhuma das matrizes tem liberação que siga taxa de liberação de ordem zero. Observa-se que a liberação é rápida nas primeiras horas do experimento, seguida de uma liberação bem mais lenta, atingindo o equilíbrio após 20 horas, como se pode observar na Figura 5.

Quando o agente ativo está disperso na matriz polimérica, a liberação é governada por um mecanismo que pode ser explicado pelo modelo de Higuchi ${ }^{[24]}$, que é um modelo aproximado e fundamentado na primeira lei de Fick. Esse modelo assume que a droga na camada superficial do sistema dissolve-se na matriz polimérica e difunde-se para fora do mesmo. Quando o teor do agente na superfície esgota-se, a próxima camada começa a exaurir. A cinética de liberação pode ser descrita pela equação de Higuchi (Equação 2), onde uma reta é esperada para a quantidade liberada em função da raiz quadrada do tempo $\left(\mathrm{t}^{1 / 2}\right)$ para sistemas baseados no mecanismo de difusão.

$$
\mathrm{M}_{\mathrm{t}}=\mathrm{k} \mathrm{t}^{1 / 2}
$$

onde $\mathrm{M}_{\mathrm{t}}$ é a quantia total de droga liberada, $\mathrm{k}$ é a constante de liberação e t é o tempo.

A Figura 6 mostra a cinética de liberação de antibiótico dos compósitos segundo o modelo de Higuchi. Verifica-se, para ambos os experimentos utilizando-se compósitos de colágeno 24 e 48 h com $5 \%$ de cloridrato de ciprofloxacina, que os gráficos da quantia de antibiótico liberada em função da raiz quadrada do tempo obedecem ao modelo de Higuchi nas quatro primeiras horas de liberação. Isto sugere

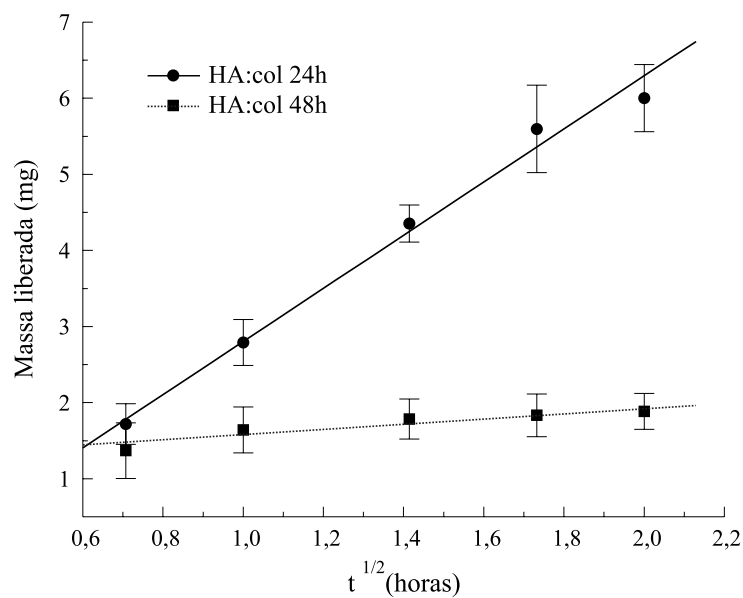

Figura 6. Modelo de Higuchi para as quatro primeiras horas de liberação dos compósitos preparados com (a) colágeno de $24 \mathrm{~h}$ e (b) colágeno de 48 h, contendo $5 \%$ de cloridrato de ciprofloxacina.

que a liberação de antibiótico a partir dos compósitos HA:col (10:1) é controlada nas primeiras quatro horas por um processo de difusão nos poros, indicando portanto que a liberação depende da porosidade do compósito ${ }^{[12,22]}$. Deve-se salientar também que a porosidade de um compósito destinado a implantes é importante porque permite o desenvolvimento de osso e tecidos moles dentro dos poros, além do suprimento de sangue para posterior mineralização do osso $^{[25]}$.

Para investigar o efeito da quantidade de droga incorporada nos padrões de liberação, realizou-se um teste com uma concentração maior de cloridrato de ciprofloxacina (10\%). Observou-se um comportamento diferente de liberação, onde o compósito HA:col 24h com mais antibiótico incorporado liberou uma quantidade ligeiramente menor, considerando-se o mesmo

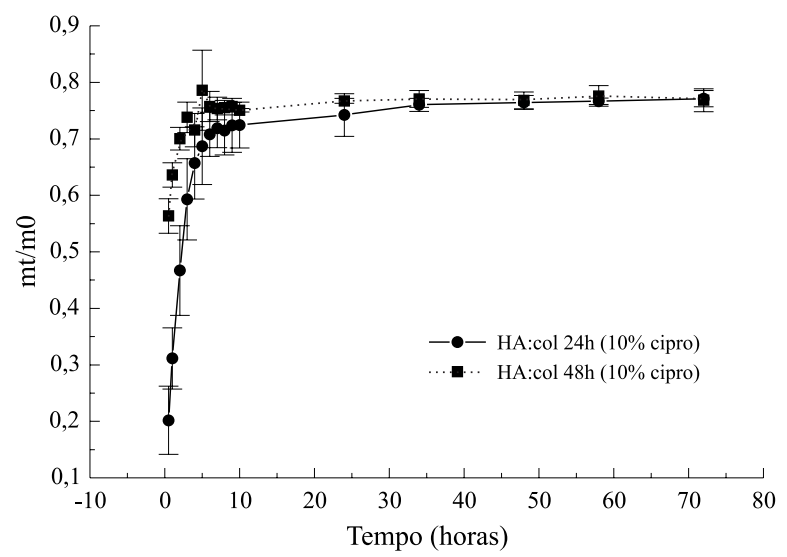

Figura 7. Comparação entre a liberação de antibiótico dos compósitos HA:Col (10:1) preparados com colágeno de tratamento alcalino de 24 e 48 horas com $10 \%$ de cloridrato de ciprofloxacina, onde mt é a quantidade total liberada e m0 é a quantidade incorporada (em mg). 


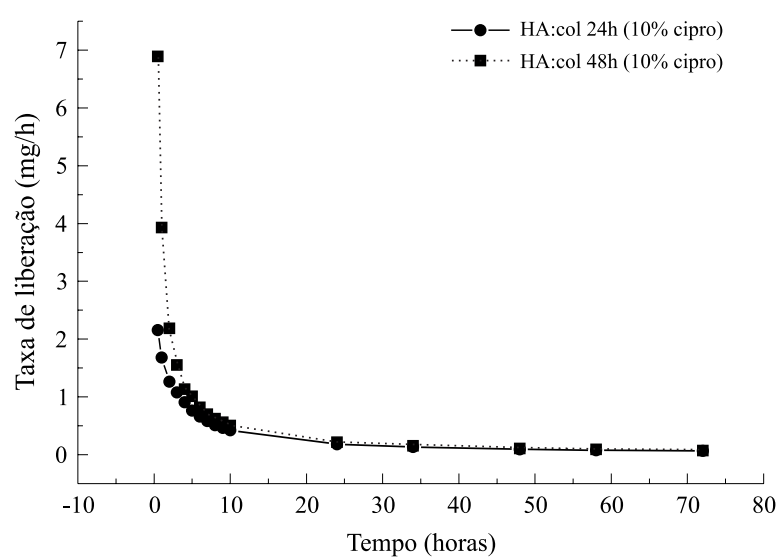

Figura 8. Comparação entre as taxas de liberação de cloridrato de ciprofloxacina dos compósitos HA:Col 24h e HA:col 48h (10:1) com $10 \%$ de antibiótico.

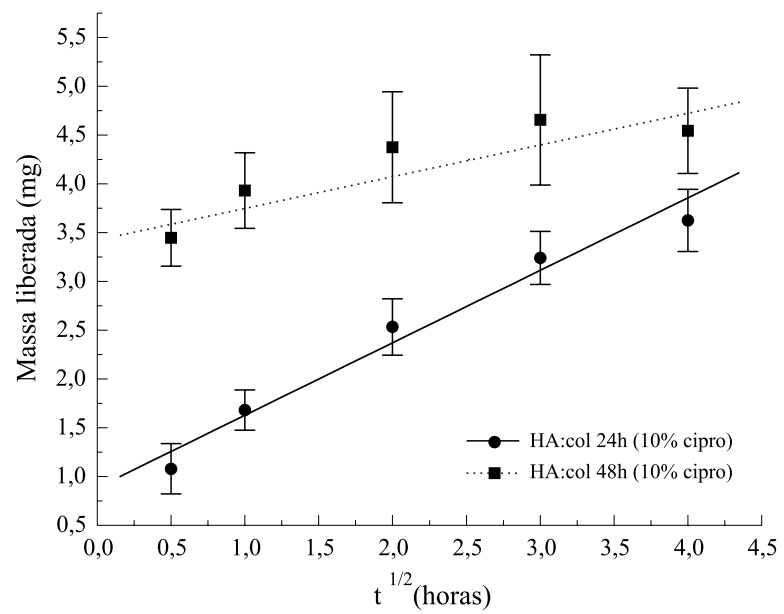

Figura 9. Modelo de Higuchi para as quatro primeiras horas de liberação dos compósitos preparados com colágeno de 24 e de $48 \mathrm{~h}$, ambos contendo $10 \%$ de cloridrato de ciprofloxacina.

tempo de experimento. Em relação ao compósito HA:col 48h, não se observou variação, com liberação de cerca de $75 \%$ de antibiótico para as duas concentrações de droga incorporada (Figuras 7 e 8).

Para os experimentos de liberação de cloridrato de ciprofloxacina em compósitos HA:col 24 e $48 \mathrm{~h}$ contendo $10 \%$ do antibiótico, observa-se que a liberação também segue o modelo de Higuchi (Figura 9), sendo que, no experimento empregando-se o colágeno de $48 \mathrm{~h}$, a linearidade do gráfico é mais evidente nos quatro primeiros pontos (referentes às três primeiras horas de liberação).

\section{Conclusões}

Os experimentos de liberação de antibiótico utilizando os compósitos HA:col 24 e 48h (10:1), mos- tram uma liberação rápida nas primeiras horas de imersão, o que impede uma concentração muito baixa do medicamento no sítio de ação no início do tratamento de uma infecção. $\mathrm{O}$ emprego de colágeno com diferentes tempos de tratamento alcalino para o preparo dos compósitos parece ter exercido influência na porcentagem de liberação de cloridrato de ciprofloxacina, provocando uma pequena alteração na taxa de liberação. Os resultados parecem indicar que a diferença na quantidade de cargas entre os colágenos provoca uma diferente interação entre o compósito e o antibiótico. Observou-se que a liberação foi controlada pelos poros da matriz nas quatro primeiras horas de experimento, pois obedece ao modelo de Higuchi neste intervalo de tempo.

Posteriormente será testada outra forma de incorporação da droga (por imersão, no compósito já pronto).

\section{Agradecimentos}

As autoras agradecem o apoio técnico de Ezer Biazin, Glauco D. Broch e Virginia C. A. Martins. C. A. Ogawa agradece à Capes pela bolsa concedida.

\section{Referências Bibliográficas}

1. Folkmann, J. - Biomaterials 11, p.615-618 (1990).

2. Baker, R. - "Controlled release of biologically active agents ", Willey-Interscience Publication, New York (1987).

3. Yaylaoglu, M. B.; Korkusuz, P.; Örs, Ü.; Korkusuz, F.; Hasirci, V. - Biomaterials 20, p.711-719 (1999).

4. Kawanabe, K.; Okada, Y.; Matsusue, Y.; Iida, H.; Nakamura, T. - J. Bone Joint. Surg. Br., 80B, p.527530 (1998).

5. Guicheux, J.; Grimandi, G.; Trécant, M.; Faivre, A.; Takahashi, S.; Daculsi, G. - J. Biomed. Mat. Res. 34, p.165-70 (1997).

6. Itokazu, M.; Yang, W.; Aoki, T.; Ohara, A.; Kato, N. Biomaterials 19, p.817-819 (1998).

7. Itokazu, M.; Sugiyama, T.; Ohno, T.; Wada, E.; Katagiri, Y. - J. Biomed. Mat. Res. 39, p.536-538 (1998).

8. Solberg, B. D.; Gutow, A. P.; Baumgaertner, M. R. - J. Orthop. Trauma 13, p.102-106 (1999).

9. Lawson, A. C.; Czernuska, J. T.; Proc. Inst. Mech. Eng. 212, p.413-425 (1998). 
10. Mann, S.; Webb, J.; Williams, R. J. P. "Biomineralization: chemical and biochemical perspectives", Weinheim, Germany, VCH (1989).

11. Metsger, D. S.; Rieger, M. R.; Foreman, D. W. - J. Mater. Sci. - Mater. Med. 10, p.9-17 (1999).

12. Martins, V. C. A.; Goissis, G.; Ribeiro, A. C.; Marcantônio Jr., E.; Bet, M. - Artif. Organs 22, p.215221 (1998).

13. Ramchandani, M.; Robinson, D. - J. Control. Release 54, p.167-175 (1998).

14. Goissis, G.; Plepis, A. M. G.; Rocha, J. L.; "Processo de extração de colágeno de tecidos animais com auxílio de solventes orgânicos e meio alcalino". BR PI 9.405.043-0 (1996).

15. Ogawa, C. A.; Plepis, A. M. G. - "Estudos preliminares de liberação de ciprofloxacina em compósito hidroxiapatita:colágeno", in: Anais do $5^{\circ}$ Congresso Brasileiro de Polímeros, p.1403-1408, Águas de Lindóia - SP, nov. (1999).

16. Ogawa, C. A.; Plepis, A. M. G. - Revista Brasileira de Engenharia Biomédica 17 (3), p.123-130 (2001).
17. Murphy, J.; Riley, J. P.-Anal. Chim. Acta 27, p.31-36(1962)

18. Laemmli, U. K. - Nature 227, p.680-685 (1970).

19. William, D. F. - "Definitions in biomaterials", Elsevier, New York (1987).

20. Diarra, M.; Pourroy, G.; Muster, D.; Zingraff, M.; Boymond, C. - Biomaterials 19, p.1523-1527 (1998).

21. Van Caekenberghe, D. L.; Pattyn, S. R. - Antimicrob Agents Chemother. 25, p.518-521 (1984).

22. Sousa, M. H. - "Estudos de incorporação e liberação de antibióticos em membranas de colágeno", Dissertação de Mestrado, Universidade de São Paulo, São Carlos (1998).

23. Dash, A. K.; Cudworth II, G. C. - J. Pharmacol. Toxicol. Met. 40, p.1-12 (1998).

24. Higuchi, T. - J. Pharm. Sci. 59 (3), 353 (1970).

25. Sepulveda, P.; Binner, J. G. P.; Rogero, S. O.; Higa, O. Z.; Bressiani, J. G. - J. Biomed. Mater. Res. 50, p.2734 (2000).

Recebido: $10 / 08 / 01$

Aprovado: 06/04/02 